\title{
Derry Girls and Containment: Conflict-related and Transgenerational Trauma in Northern Ireland
}

Long, M. (2021). Derry Girls and Containment: Conflict-related and Transgenerational Trauma in Northern Ireland. Journal of Psychosocial Studies, 14(1), 3-17. https://doi.org/10.1332/147867321X16104825689759

Link to publication record in Ulster University Research Portal

\section{Published in:}

Journal of Psychosocial Studies

Publication Status:

Published (in print/issue): 01/03/2021

DOI:

$10.1332 / 147867321 \times 16104825689759$

\section{Document Version}

Author Accepted version

\section{General rights}

Copyright for the publications made accessible via Ulster University's Research Portal is retained by the author(s) and / or other copyright owners and it is a condition of accessing these publications that users recognise and abide by the legal requirements associated with these rights.

\section{Take down policy}

The Research Portal is Ulster University's institutional repository that provides access to Ulster's research outputs. Every effort has been made to ensure that content in the Research Portal does not infringe any person's rights, or applicable UK laws. If you discover content in the Research Portal that you believe breaches copyright or violates any law, please contact pure-support@ulster.ac.uk. 
Derry Girls and Containment: Conflict-related and Transgenerational Trauma in Northern Ireland

\section{Dr Maggie Long}

Ulster University, Jordanstown, Faculty of Arts, Humanities and Social Sciences, Northern Ireland.

This is a post-peer-review, pre-copy edited version of an article published in Journal of Psychosocial Studies. The definitive publisher-authenticated version [Long, M. (2021) Derry Girls and containment: conflict-related and transgenerational trauma in Northern Ireland, Journal of Psychosocial Studies, vol 14, no 1, 3-17, DOI: 10.1332/147867321X16104825689759] is available online at:

https://www.ingentaconnect.com/content/tpp/jps/2021/00000014/00000001/art00001

\section{Abstract}

In this article, I consider role of the television show Derry Girls in providing containment for the unbearable aspects of conflict-related and transgenerational trauma in the context of Northern Ireland. Derry Girls is a situation comedy set during the political conflict of Northern Ireland in the 1990s. The show provides nostalgic, satirical and affectionate observations on the seemingly mundane and at times farcical misdemeanours of a group of young people living out their every day lives in the backdrop of sectarianism, bigotry and political violence. First airing in 2018, 20 years after the peace agreement in Northern Ireland, Derry Girls offers a forum for experiencing a flavour of life in the height of the Troubles, evoking strong emotional reactions in audiences through laughter, consternation and tears. I consider the role of psychosocial studies in framing understanding of the show as a cultural outlet for and container of societal level trauma and collective pain.

\section{Key words:}

Conflict-related trauma; transgenerational trauma; containment; psychosocial; popular culture 


\section{Introduction}

Derry Girls is a coming-of-age situation comedy that charts the foibles and misdemeanours of a group of four teenage girls: Michelle, Erin, Orla, Claire, and one boy: James, in keeping with the cultural frame of shows such as 'The Inbetweeners' or 'Freaks and Geeks'. However, Derry Girls is uniquely distinguished by the sociopolitical context, which forms its backdrop. The series is set in Derry, a city in the North West of Northern Ireland (NI), during the 1990s in the midst of the political conflict known as 'the Troubles'. Derry Girls is written by Lisa McGee, loosely based on her own experiences as a teenager growing up in Derry in the 1990s and "in between the gags and the set-ups, the series highlighted the ubiquity of the Troubles in everyday life and, by extension, its normalcy" (Ganatra, 2019). In the series, we see teenagers grappling with typical challenges around friendship, sexuality and authority interlaced with a sharp political sub-text that includes scenes of soldiers patrolling the streets, news footage of bombs, and searing observations on Anglo-Irish relations. In writing this article, I draw upon reflections and insights gained from my combined professional experiences, as an educator with an interdisciplinary background in sociology, literature, and psychodynamic counselling, previous roles as a suicide intervention counsellor in Belfast, and personal experiences of growing up and living in NI and being a fan of the show Derry Girls.

\section{The NI Context}

NI is a region of the United Kingdom (UK) that endured more than 40 years of political conflict, often euphemistically referred to as the 'Troubles', which ended in 1998. The conflict was based on political differences between Catholic/Nationalists, who sought for NI to be united with the Republic of Ireland, and Protestant/Unionists who wished to remain in the UK. This political conflict was recognised to be the most intensive and violent to unfold in Europe (Muldoon, 2004). Approximately 3,720 people died during the conflict and many more were injured (O'Neill et al., 2015), leaving a legacy of trauma that ricochets throughout Northern Irish society despite the progress made in the 22 years since the Good Friday Agreement. The Good Friday Agreement in 1998 formally signified the beginning of peace in NI; a peace agreement voted for by the people, 
it was designed to ensure that everyone in NI could live together without segregation, discrimination and violence. Derry Girls was aired in 2018 on UKwide Channel 4, significantly in the year that marked 20 years since the Good Friday Agreement. Moreover, the show aired during a period of huge political uncertainty in the UK, NI and the Republic of Ireland, brought about through Brexit as well as the political stalemate in NI where the devolved government ceased to operate in 2016 (Morrow, 2018), with major ramifications for everyone, but notably for the most marginalized.

There has been much progress in NI in the twenty years since the Good Friday Agreement. Life for most people is much more 'normal' than it was during the decades of conflict. Bombs and shootings are no longer regular occurrences and we no longer all hear the constant din of helicopters above our heads. However, experts in Peace and Conflict (Hayward \& McManus, 2019) describe NI as a PostAgreement society rather than Post-Conflict because of the fluidity of the transition from conflict to peace, and, as discussed below, there remain areas of NI that are still very much impacted by conflict. The ripple effects of the conflict feed into many areas of life in NI.

There are sharp socio-economic divides, exacerbated by the selective education system, which compounds a persistent and significant class-based attainment gap. In this education system, at age 10-11, children compete for grammar school places by undertaking rigorous academic testing. Children from backgrounds of social disadvantage are consistently under-represented in grammar schools, an inequality shaping the landscape of NI's education system since the 1940s. The real impact of this inequality is stark, given that attendance at grammar school is a strong predictor of both educational attainment and destination following secondary level education (Burns, Leitch \& Hughes, 2015). Furthermore, for more than a decade, working-class protestant males are reported to be consistently under-achieving in education and an expert group has recently been established to address this inequality (Department of Education, 2020). 
Hayward \& McManus (2019) show that according to the NI Life and Times Survey, the largest proportion of the population in NI today do not identify as Unionist or Nationalist but Neither. Nonetheless, issues of Irish/Nationalist/Catholic and British/Unionist/Protestant concern continue to raise their head. For example, flag protests held about the decision to fly the Union flag on public buildings on designated days as is practice in other parts of the UK, and the opposition to a proposed Irish Language Act. Issues of flags and the Irish Language Act have been identified by some in the political arena as attempts to infringe upon and erode Unionist identity, which has contributed to public discord and the recent political lockdown 2016-2020 (O'Caollai, 2020). However, for most people in NI, there is a desire for politicians and the political establishment to focus their energies on 'bread and butter issues' of health, education, housing, and unemployment. Health and educational inequalities are mainstay issues, not helped by either the political stalemate in NI or the inadequate budget from Westminster.

Despite the many problematic legacy issues, there also exists a vibrant, grassroots community activism in $\mathrm{NI}$, where community groups and organisations work tirelessly to repair the damage of the past and build for the future. NI is a unique place, borne out in the character of its people, undoubtedly tarnished by its past but undeniably replete with a strong sense of community, resilience and compassion. Derry Girls perfectly captures the idiosyncrasies of NI through the characters, dialogue, and storylines, some of which I discuss below.

\section{Derry Girls}

At once profane and profoundly moving, Derry Girls has been an emotionally evocative entry into local discourse in NI. The very title risked controversy, as the city Derry is also known as Londonderry, and choice of terminology often acts as a signifier of national identity, with the prefix London signifying 'Britishness' and its omission, by contrast, 'Irish-ness'. Similarly, in the title, the word 'Girls' marks the show out for representing the plights of teenage girls, so often rebuked and diminished in mainstream media, which has recently been recognized to have contributed to the upsurge in mental health problems in girls 
and young women whose very real struggles have been trivialized and overlooked at a systemic level by policy-makers (Mental Health Foundation, 2018). So in Derry Girls we have an unlikely hit, focusing on a forgotten demographic in an overlooked corner of a conflicted region, which transcends fractured identities and temporarily facilitates relief, release and cohesion, in an otherwise fragmented space.

The Derry Girls are Erin, Orla, Clare, Michelle and James. The protagonist is Erin, a teenage girl with ambitions beyond the Derry world she inhabits and for which she is subjected to frequent banter by her family and friends. Erin's family home forms the familial backdrop of the show, through which we gain insight into her family dynamics. Erin lives with her mother Mary, father Gerry from Dublin, grandpa Joe (Mary's father) and a baby sibling. Erin's cousin Orla and her mother Sarah are central characters in the family. Sarah is Mary's sister, who might appear whimsical, for instance claiming to be psychic, "I took a course, I got a certificate", yet is often startlingly direct, "Can you not get protestant lesbians?". Orla presents as the quintessential clown of the Derry Girls group, whose seeming naivety is interspersed with her tendency for literal interpretations. Some of her lines offer sharp observations that juxtapose hilarity with sobering insight into many aspects of Northern Irish culture. For instance, "You shouldn't swear, Michelle. Our lady in heaven; she cries tears, then makes rain", a tonguein-cheek allusion to staunch Catholic beliefs, while Orla is sincere, the audience is amused.

The relationship between grandpa Joe and Gerry offers sharp commentary both on in-law relationships at an interpersonal level and on North-South Irish relations at a sociopolitical level. In series 1 Grandpa Joe makes the quip of an over-protective and envious father, "why can't you leave our Mary alone?" to which Gerry replies, "we've been married for 17 years!" Referring to Gerry as "that free-state fucker", conveys the oft antagonistic relationships between people from NI and those in the Republic of Ireland. The Republic of Ireland was known as "the Free State" following Irish Independence from England, after the Irish War of Independence 1919-1921. In 1921 partition came into effect in 
Ireland, and NI was formed to remain in the UK. The term "Free State" is sometimes used contemptuously by Nationalists in NI who have felt betrayed or left behind. Interestingly Leo Varadkar, the former Taoiseach of Ireland, made a powerful statement on Brexit negotiations in December 2017, just one month before Derry Girls first aired, in which he said to the people of NI "You will never again be left behind by an Irish Government" (Fine Gael, 2017). Joe's use of the term with Gerry renders this often unspoken and uncomfortable sentiment, both audible and palpable.

Clare presents herself as the altruistic idealist, who frequently sells out her causes, for instance vowing to fast to raise money for Ethiopia, only to break the fast within a few hours. In some ways she represents a young person in moratorium, making a range of identifications, for example, idealistic, political, rebellious, only to cast each aside when challenged by authority figures. When the group gets in trouble in school Clare quickly launches into a monologue with the principal Sister Michael to blame Michelle, "if anyone should get in trouble it should be Michelle", to which Sister Michael replies, "Well I think it's safe to say we all just lost a bit of respect for you there Clare." In the finale of series 1 Clare comes out as lesbian and her character affords us painful insights into the experiences of young people who identified as same-sex attracted, growing up in NI in the 1990s. We see in plain light the homophobic views of her peers worked through as they realise and eventually accept their friend's sexuality.

Michelle is a loud-mouthed, 'trouble-maker' with a heart of gold. Her constant insults of her friends and antics that lead them all into trouble is underscored by her fierce loyalty, which she is at pains to portray. In the finale of series 1 when the other schoolgirls are mocking Orla's step aerobics performance at the school show, Michelle states boldly, "she might be a dick, but she's our dick" before joining her friend on the stage. We see Michelle reveal her closely guarded sensitivity again in her interactions with her cousin James at the end of series 2 . James, discussed in more detail below, is the cousin of Michelle. He has moved to Derry from England where he grew up, and in his character, we see the experience of outsiders in the insular world of NI. Through both series, we 
become aware of James' pained relationship with his mother, an inconsistent figure who uses and manipulates him for her own gain. The pain of this relationship is poignantly represented in series 2 when she returns to bring him back to England, with James' longing to repair the damage of their relationship and subsequent realisation that his mother's gestures of repair are insincere. In the season finale, we see the growth of James and Michelle's often conflictual relationship. At this time in her own abrasive way, Michelle helps James to see the painful reality that his mother will "let [him] down again" and to recognise that with his family and friends in Derry, he has at last found love and belonging, “you're a Derry Girl now James...being a Derry Girl, it's a fucking state of mind."

\section{Derry Girls and Sociopolitical Commentary}

An anomaly with the series' title comes in the form of James; a character who offers a fascinating glimpse into sociopolitical discourse in NI, with both historical and contemporary relevance. Rather than a Derry girl, James is an English boy, albeit of Derry-descent, treated with sardonic contempt and repeatedly ridiculed for being "English" and "gay", both of which are ultimately represented as equivalent to the slight of femininity. He is introduced in the first episode by his cousin Michelle, as the son of her auntie Cathy "who travelled to England years ago to have an abortion, and never came back, never got the abortion either, lucky for you James, eh". His voice, accent and national identity are mocked from the outset "he's English, that's the way they talk". In the first episode we note that in having to attend the girls' convent school because it would not be safe for him attend the local boys' school, "because unfortunately for James, he's English", he is not even provided with a toilet. He becomes the quintessential disdained coloniser, represented in dialectical opposition to the locals. James initially is maligned by the locals in ways reminiscent of O'Casey's Charles Bentham (1924), in Juno and the Paycock. Bentham as the outsider in another scathingly political drama set during the Irish civil war, which used dialectical configurations to comment on the social ills and consequences of war (Schrank, 1975). Represented as undeserving of having his basic needs met, this sub-plot in the first episode is executed in a slapstick portrayal of mayhem that renders the fiercely political undercurrent tolerable for audiences. 
James offers powerful political commentary on the NI of the past and present. NI is a distinctly patriarchal and heteronormative society, underpinned through policy and law. Only on 22 $2^{\text {nd }}$ October 2019 did same-sex marriage and abortion become legal in NI, finally moving in line with the rest of the UK, after many years of political lobbying and grass-roots campaigns. This was a historic moment that the largest political party in NI attempted to thwart up until the eleventh hour (Carroll, 2019), starkly conveying the religious conservatism that dominates systems of government and public services. Socio-religious divides prevail in NI, with religious segregation of government and education systems. Further, social divisions on the basis of poverty, social deprivation, sectarianism, violence and racism are pronounced in areas that experienced most exposure to the conflict (Muldoon, 2004).

Research based in NI has provided evidence of prejudicial attitudes towards groups including women, same-sex attracted people, young people, black and ethnic minorities and other marginalised groups (Bloomer and Fegan 2014; Horgan 2011; Muldoon 2004; Schubotz and O’Hara 2011). Charles (2019) suggested that the marginalisation of out-groups renders oppression invisible and restricts capacity for growth, yet "Encountering otherness with respect is crucial to our ability to engage meaningfully with one another" (p. 119). In a literary sense James might well be viewed as a foil, but framed in the sociohistorical context his character offers potent political commentary. Through James the nods to national identity, abortion, sexuality and femininity speak powerfully to an intolerance of difference and a societal push for fixed identities that render dysfunctional sociopolitical conditions bearable in the short-term but ultimately inhibit growth and reparation.

\section{Derry Girls: Societal and Transgenerational Trauma}

Psychoanalytic theory on defence mechanisms, in particular the concepts of splitting and projection, provide invaluable understanding of the psychic processes that underpin stereotype, prejudice and discrimination. Psychic defences are mechanisms used to protect us against psychic pain (Lemma, 
2016). Defences defend us against the anxieties, sense of impending danger, we feel in situations that resonate with our earliest object relations, or relating with primary caregivers (Quatman, 2015). Feeling the full force of those anxieties and the psychic pain they relate to, could be so unbearable, that defences are employed unconsciously to protect us from fragmenting or "going to pieces" (Hinshelwood and Fortuna, 2017, p. 96). Defences are a ubiquitous, inevitable aspect of being human. Furthermore, defences provide an essential means of survival for people who experience trauma and adversity in childhood (Lemma, 2016). However, when we continue to employ defences to defend against a threat that no longer exists, life's meaning becomes shaped by survival rather than living. This seems relevant to the sociopolitical context of NI, where societal level trauma has shaped our capacity to relate to ourselves and others, as if we are defending against threats to our survival.

Primitive defences are those established pre-verbally in infancy, and thus are representative of the paranoid-schizoid position (Howard, 2010; Joseph, 2005; Klein, 1946; Lemma, 2016). Paranoid-schizoid relates to the mental state of infants during the first six months of life approximately, whereby the baby experiences overwhelming fears of annihilation, persecutory anxiety, or fear for the self (Klein, 1946). When the baby feels nourished, s/he perceives the good breast as nurturing, when in need of comfort, warmth, food, the baby feels hostility and anger towards the bad breast that withholds. During times of stress, we often revert to the paranoid-schizoid position (Joseph, 2005), where we experience fears of annihilation, which we attempt to tolerate through splitting and projection (Hinshelwood, 2008; Howard, 2010; Joseph, 2005). Splitting involves separating off those aspects of our personality that we cannot tolerate and projecting them on to another object, so that the other becomes either allbad or all-good, depending on the qualities we perceive them to hold.

Splitting and projection essentially form the basis of stereotype, prejudice and discrimination, whereby 'others' are perceived to be all-bad, embodying those qualities we are incapable of tolerating within ourselves. In Derry Girls, we see this notably in the first episode of series two, with 'the Blackboard scene'. On a 
"cross-community" trip, a common feature of life for children and young people from NI, the young people from Catholic and Protestant backgrounds write common stereotypes about the 'other' group in a brainstorming session on the blackboard. These include direct comparisons such as "GAA vs Football”, with GAA referring to the Gaelic Athletic Association sports versus soccer, and the more seemingly outrageous, "Protestants keep toasters in the cupboard" and Catholics "keep coal in the bath." Described as "comedy gold" by mainstream local media (Belfast Telegraph, 2019), the blackboard observations indicated deeply held stereotypes about the morality of the other, with the toaster and bath comments implying either fastidiously uptight or slovenly and unclean. In providing a space for us to laugh at or with the stereotypes that ridicule the basis of the political conflict, Derry Girls offers a cultural container for generations of bigotry, sectarianism and intolerance that underpinned and reinforced political violence in NI. In doing so, Derry Girls subtly urges us to challenge our own assumptions and begin to contain our own distress. This challenge is no mean feat in the context of contemporary NI where emotional distress as a consequence of the political conflict inhabits the space within and between all of us, often beyond our awareness.

The enduring legacy of the political conflict in NI is borne out in the mental health of the population. In 2018 it was reported that with 4,918 deaths by suicide between 1997-2017, more people had died by suicide in the 20 years since the GFA than died during the political conflict (NI Statistics and Research Agency, 2018). NI has the highest population suicide rate in the UK at 16 per 100,000 , and at 25 per 100,000 the male suicide rate is twice that in England (O'Neill \& Hamber, 2018). Both population prevalence of mental health problems and population suicide rate are higher in NI than other regions of the UK and Western Europe (Bunting et al. 2013; O'Connor, Hawton and Rasmussen 2014; O'Neill et al. 2014; Tomlinson 2012). Muldoon \& Downes (2007) found that $10 \%$ of participants in a telephone survey in NI $(n=3000)$ reported symptoms suggestive of clinical Post-Traumatic Stress Disorder (PTSD). In large-scale psychological research $(n=1986)$, it was found that $39 \%$ of the NI population experienced at least one conflict-related trauma and 31\% experienced at least 
one non-conflict related childhood adversity (Bunting et al, 2013; McLafftery et al. 2018). Furthermore, rates of prescription drug use are high (Benson et al., 2018) and anti-depressant prescribing costs are consistently higher in NI than other regions of the UK (Mental Health Foundation, 2016). The lack of devolved government in NI has created crises in public services, with sorely inadequate funding for mental health services in a context of severe need. The consequences are most severe among communities exposed to the most intensive violence of the political conflict, where poverty, segregation and violence persist and rates of suicide are highest (Tomlinson, 2012).

In Derry Girls we are reminded of how for generations, political tensions and violence were a normalized part of every day life. In the first episode of the first series, Aunt Sarah remarks, "I'm not enjoying this bomb. I've an appointment in Tropicana at 12 ... sure I'll not get over the bridge at this rate." Commenting on the show and about walking the line of appropriate comedy, the Derry Girls writer Lisa McGee stated, "But because I grew up there, I have a good sense of where the line is. I know bomb scares were so frequent they became mundane. I know people complained about not being able to get to the shop" (Ganatra, 2018). Similarly, teenage girls commenting on the army patrolling the streets, exclaiming that the soldiers "are rides", "rides" being Northern Irish slang for attractive, conveyed how young people accommodated the dysfunctional social conditions into their everyday concerns. Thus Derry Girls offers a visceral reminder of how people in NI navigated those every day traumas. Drawing on psychosocial studies elucidates awareness of the Derry Girls effect in creating a space to remember those everyday traumas that those of us who lived through the conflict carry in varying degrees and continue to act out in our relationships with ourselves and the world around us.

From a psychosocial lens, trauma is transmitted from one generation to the next through projection and projective identification, whereby "hauntings" of trauma are carried by the next generation in a liminal space of knowing and not knowing (Woodward, 2015). Danieli (1998) referred to a "conspiracy of silence", of societal level silencing and avoidance, which generates the transgenerational 
transmission of trauma to younger generations who never experienced the original trauma. This societal silencing in NI is captured perfectly by Heaney in his anthology, 'North', published during the height of the conflict in 1975. In his poem, "Whatever you say, say nothing”, Heaney (1975) writes of:

"The famous

Northern reticence, the tight gag of place And times".

Both the poem's title and content communicating the cultural ethos of community lockdown in NI at that time, "Whatever you say, say nothing". Speak nothing of the pain and trauma enslaving the essence of life. Yet as Charles (2019) succinctly articulated, "What is not faced by the parent haunts the child" (p. 121). A societal reticence transmitted to future generations, among whom today mental health problems, substance abuse and suicide loom large as consequences of carrying the burden of the previous generation's trauma, avoidance and silence. Downes, Harrison, Curran \& Kavanagh's (2012) in-depth qualitative research based on mothers' experiences of multigenerational trauma in NI suggested that trauma persisted into the lives of their children through repetition and unconscious processes. Furthermore, large-scale psychological research on suicide, mental health and childhood adversity in NI, provides evidence of this transgenerational transmission of trauma, whereby younger generations who were not exposed or were exposed minimally, to the political violence, are impacted by the ripple effects in the aftermath of the trauma (O’Neill et al. 2014; O’Neill et al. 2015; McLafferty et al. 2018).

Younger generations in NI, colloquially termed the "peace babies", born on or after 1998, who never witnessed the political violence, have endured both the psychological and sociopolitical fallout thereof. Growing up in a context of silencing and avoidance means that, "people can be fearful of their own tears, somehow experiencing this as diminishing their status in the eyes of others. Freud teaches us ... of the need to give time and space to mourn, of the emotional consequences if these opportunities are missed and of the years it can take to open up the grief that we learn to carry silently as a potential kind of haunting disturbance" (Seidler, 2013, p. 57). In Derry Girls, we see the caustic 
humour so characteristic of Northern Irish culture, manifest in the sardonic wit of Sister Michael, in the wry jibes at Erin's diary where she refers to herself as a "child of war", and Michelle's repeated acerbic statements to her friends, "don't be a dick", and "wise up". NI's culture of "slaggin'”, an idiom for tongue-in-cheek teasing, is part and parcel of every day life where emotional expression is treated with either contempt or ridicule. Resonating with Kesey (1962), "you have to laugh at the things that hurt you, just to keep yourself in balance, just to keep the world from running you plumb crazy" (p. 237), the laughter serves an important purpose; survival in debilitating social conditions, but it comes at a grave cost when we consider the anguish and pain of repressed trauma.

In contemporary NI societal level trauma is pervasive; paramilitary activities continue in many communities including violence against members of the paramilitary's 'own' communities in so-called "punishment attacks" (Monaghan \& McLaughlin, 2006), and "peace walls" designed to segregate and prevent conflict in interface communities remain, still providing the role "of protection and safety by separation" for local residents twenty years after the ceasefires (Byrne, Gormley-Heenan, Morrow \& Sturgeon, 2015, p. 15). Drug use in young people has increased, with shifting patterns in drug use whereby a wider array of both prescription and illegal drugs are more readily available on the streets (Department of Health, 2017). Issues of drug addiction and homelessness are tangible realities on the streets of Belfast, the capital city of NI, and beyond. Suicide in young people has tragically ripped through families and communities, with rates in under 18s disproportionately higher than other regions of the UK (Black, 2019). In writing about trauma, Hannah Curtis (2015) explains, "If we have known the experience of being supported and helped through a trauma we can grow and learn from it, but if our emotional responses to trauma have been misunderstood or dismissed or even punished, we will not have been given the opportunity to remember and work through and we will be much more likely to repeat, to act out, to express our feelings in confusing and sometimes unacceptable ways" (p. 16). Young people in NI carry the trauma of the past, and without adequate opportunities for healing and expression, the pain and burden become unbearable, tolerated through self-medication and self-destructive 
behaviours.

\section{Derry Girls: Trauma and Containment}

Where trauma and terror are projected onto and into subsequent generations, containment, a concept developed by Bion (1962) offers the possibility of containing and processing such distress. Developed by Bion (1962), who built upon the work of Klein (1946) and Winnicott (1960), containment relates to the symbiotic relationship between mother and infant in the earliest stages of life, which is reproduced in the therapeutic encounter, to facilitate integration and development of the self (Bion, 1962; Britton, 1998). In Bion's (1962) model, in a clinical setting containment is an interactive process between therapist and patient, whereby the patient's unassimilated psychic material, in the form of trauma or other overwhelming experience, is detoxified and meaning is created. The clinical application of containment renders unbearable states of mind tolerable, "the containing function represents an area of mind or mental connection that attempts to find ways of tolerating undeveloped psychic content and emotions so they can be held in mind and understood" (Cartwright, 2010, p. 5). The functions of containment in therapy are to provide a safe, boundaried space to detoxify and to make meaning from distressing emotions and experiences (Britton, 1998). Gradually, the patient can introject meaning from the therapist, which enables them to contain their own experience, to develop their own insight and strengthen their sense of self (Hinshelwood \& Fortuna, 2017).

In earliest life, the newborn baby feels terror at the threat of annihilation, which she projects into her mother, who receives the projections, introjects the betaelements $(\beta)$ (Bion, 1962) and gains insight into the infant's state of mind (Hinshelwood \& Fortuna, 2017). If all goes well, and the mother is able to receive and identify with the baby's state of mind, while maintaining her own perspective, a state of mind termed "reverie" (Bion, 1962), the mother meets the baby's needs appropriately, most of the time. By giving back meaning through experiences that the baby can handle, alpha-elements $(\alpha)$ (Bion, 1962), the mother facilitates the baby beginning to build a sense of meaning from 
previously unbearable experiences. For example, the baby begins to understand the feeling of hunger, which can be satiated with food. If the mother is unable to contain the baby's distress, and in some cases might project even worse terrors back into the baby, from her own state of mind, for instance if she is living in social conditions of violence, threat and terror, the baby will not have the capacity to build up a reservoir of meaning-making experiences (Hinshelwood \& Fortuna, 2017). In a clinical setting, Britton (1998) posits that patients who have experienced problems with maternal containment respond well to the psychoanalytic psychotherapist's use of containment. In modelling the motherbaby relationship in therapy, the psychotherapist contains the patient's projections $(\beta)$, introjects them, so that they can be worked through, " 'detoxified' and permitted to gather new meaning” (Cartright, 2010, p. 141), ( $\alpha$ ), when the patient has developed sufficient capacity to tolerate them.

In the field of psychosocial studies, psychoanalytic concepts are applied to sociocultural processes, recognising that shared experiences are represented in culture and subsequently held in mind by audiences in the shared experience of cultural consumption. As containment is an interactive process in the psychoanalytic clinic involving therapist and patient, its operation in relation to a TV series does not directly parallel with clinical experience. Recent developments in the field by Noreen Giffney (2021) relate specifically to containment in cultural encounters. Giffney (2021) has formulated a new clinical concept, the culture-breast, and a new pedagogic approach, the cultural encounters case study method, relating to the psychical operation of containment when provided by cultural objects (Giffney, 2021). Giffney's (2021) work shows that in cultural encounters, the audience is not a passive recipient, "while cultural objects provide something, they also demand something from the subject in return, even if the subject is not aware of the demand or their reaction to it" (in press). In her analysis of the film Shame, Giffney $(2015,2021)$ writes of the scenes towards the end of the film, where the protagonist Brandon pushes himself to breaking point after an argument with his sister; he embarks on a heavy drinking session, initiates a fight in a bar, and is subsequently having a threesome and using drugs. In these scenes, the audience witnesses "severe 
splitting to the point of fragmentation" (Bott Spillius et al 2011a, p. 345), resulting in the experience of "a confusional state", through which Giffney facilitates, "discussions about how one might hold one's position in the consulting room when flooded by the patient's projections" (in press). Giffney's (2021) pedagogical method of facilitating the experience of encounters with cultural objects, "evokes experiences" for reflection, and "encourages meaningmaking" (in press), thus operationalising a space to experience containment through cultural objects including art, photography, literature, music, and film.

Sayers (2004) suggested that psychoanalysis too often overlooks the outward healing capacity of art. Drawing on the work of Kristeva, Stokes and Bion, Sayers (2004) explored the transformative potential of the absorption engendered in contemplating a work of art. Sayers (2004) related that Bion likened the work of the psychoanalyst to that of an artist, who senses the ß-elements of experiences and by producing a work of art, renders form that might be digested as $\alpha$ elements, by others contemplating the art, who were unable to digest the original unassimilated experiences. Discussing Bion's influence on Adrian Stokes, Sayers (2004) stated of Bion's (1965) book Transformations, which focused on the visual arts, "just as Monet transformed inner impressions into outer form, psychoanalysts likewise transform into outer form the inner formlessness and fragmentation contributing to their patients' ills, thereby making them and this formlessness bearable, whole and well" (pp. 790-791). Bion (1965) recognised the transformative role of outwardly experiencing a work of art, creating form from formlessness and rendering unbearable experiences tolerable. The experience of containment could be evoked spontaneously through healing absorption in a work of art, which envelops and enwraps, creating oneness from fragmentation. Much like visual arts, popular culture is produced by an artist, a writer, who is able to digest the sense data, and re-produce in more bearable form experiences that were hitherto intolerable. Thus, an interaction unfolds between objects, in this instance the writer and audience, who are by no means passive recipients, resonant of the interaction between the visual artist and contemplator of the work of art, and the psychoanalyst and analysand. In this 
way I propose that Derry Girls offers the possibility of containment for the unbearable experiences of conflict-related and transgenerational trauma.

According to Woodward (2015), cultural representations offer shared spaces for working through the pain of collective trauma. Cultural expression in the form of film, theatre, art and literature is understood to give voice and representation to unspoken and repressed collective trauma (Woodward, 2015). Woodward (2015) stated, “... public expressions and representations such as memorials, films, and plays serve the therapeutic role that is so much a part of analysis in the consulting room in cases of personal individual cases of trauma, of speaking that which is too painful to speak, and of making conscious what has been repressed in to unconscious" (p. 117). In the case of the collective trauma of the political conflict of NI, I suggest that the shared and intergenerational experience of watching the TV series Derry Girls, set during that conflict, opens up a space in which to project our unbearable and unspeakable emotions in relation to the conflict and its persistent legacy, which when subsequently detoxified, spoken and narrativised, become more tolerable than they were before experiencing the emotional expression facilitated by watching the show.

Derry Girls facilitates our experience of unspoken collective trauma most poignantly through the emotive ending in the last episode of the first series. The scene of the teenagers dancing freely on the school stage is juxtaposed against the scene of the parents watching mournfully the news footage of a bomb, and returning to the face of the usually derisive Sister Michael looking on from the side of the stage with sorrowful eyes and lips pursed, the latter a very real representation of the older generation's protective silence of the younger generation. A protective silence that serves its purpose in the short-term but in the long-term translates adversity in to trauma by denying memory, expression and connection.

This scene of the news reporting the bomb is poignantly reminiscent of the Omagh bomb, which was detonated in Omagh town by a paramilitary splinter group on the afternoon of Saturday 15th August 1998, killing 29 people. Most 
people in NI who are old enough to remember Omagh, remember that it sent shockwaves reverberating throughout NI. Kapur (2001) reflected on Omagh as the beginning of the reparative impulse in NI, at which point, as a collective, Northern Irish society moved from splitting and projection, the 'us versus them' mentality, and fear for self, characteristic of the paranoid-schizoid position to the concern for others and urge to repair, characteristic of the depressive position. Omagh marked a significant turning point in NI's history, where the community stood together with the conviction that no such atrocity could be inflicted upon our society again. In Derry Girls, watching the adults' concerned faces and pursed lips felt like watching hope be extinguished, and powerfully portrayed how within moments, tragedy could rip through society to freeze, isolate and silence us all. In those instants the everyday concerns, cajoling and laughter become nebulous fragments of a forgotten world filled with love, and instead now imbued with fear.

\section{Conclusion}

Derry Girls gives voice and representation to the collective trauma of the past in $\mathrm{NI}$, facilitating an environment wherein we could weep repressed tears and have both "time and space to mourn" (Seidler, 2013, p. 57). In enabling us to access and experience memories and feelings from the past, rather than "despising it as nonsensical and under-estimating its importance" (Freud, 1914, p. 152), Derry Girls affords us a cathartic cultural space. By speaking of collective trauma and repressed memories, Derry Girls provides a vehicle for catharsis and potential for meaning making from previously unbearable memories and experiences. Thus, Derry Girls acts as a container for society's projections, facilitating the collective capacity to detoxify and gain new meaning from past trauma.

\section{References}

Benson, T., Corry, C., O’Neill, S., Murphy, S., Bunting, B. (2018) Use of prescription medication by individuals who died by suicide in Northern Ireland. Arch Suicide Res, 22, 1, 139-152. https://doi.org/10.1080/13811118.2017.1289870

Bion, W. (1962) Learning from Experience. London: Karnac. 
Bion, W. (1965). Transformations. London: Heinemann.

Black, L. (2019) Suicide statistics and strategy in Northern Ireland. Research Matters. Belfast: Northern Ireland Assembly.

https://www.assemblyresearchmatters.org/2019/02/27/suicide-statistics-andpolicy-in-northern-ireland/

Bott Spillius, Elizabeth, Jane Milton, Penelope Garvey, Cyril Couve and Deborah Steiner (2011a). Paranoid-schizoid position. In The New Dictionary of Kleinian Thought. London and New York, NY: Routledge.

Britton, R. (1998) Belief and Imagination: Explorations in Psychoanalysis. East Sussex and New York: Routledge.

Bunting, B.P., Ferry, F.R., Murphy, S.D., O’Neill, S.M., Bolton, D., (2013) Trauma Associated with Civil Conflict and Posttraumatic Stress Disorder: Evidence from the Northern Ireland Study of Health and Stress. Journal of Traumatic Stress, 26, 134-141.

Burns, S., Leitch, R. \& Hughes, J. (2015) Education Inequalities in Northern Ireland: Summary Report. Belfast: Equality Commission Northern Ireland. Available from:

https://www.equalityni.org/ECNI/media/ECNI/Publications/Delivering\%20Eq uality/EducationInequality-SummaryReport.pdf

Byrne, J., Gormley-Heenan, C., Morrow, D., \& Sturgeon, B. (2015). Public Attitudes to Peacewalls. Survey Results. Belfast Department of Justice. Retrieved from: https://www.ulster.ac.uk/ data/assets/pdf file/0015/224052/pws.pdf

Carroll, R. (2019) DUP to return to Stormont to protest against abortion rights. The Guardian, 21 ${ }^{\text {st }}$ October 2019. Retrieved from: 
https://www.theguardian.com/politics/2019/oct/21/dup-stormont-protestagainst-abortion-rights

Cartright, D. (2010) Exploring Bion's 'Container Model' in Psychoanalytic Psychotherapy. London and New York: Routledge.

Charles, M. (2019) Trauma, identity and social justice. Psychoanalysis, Culture \& Society, 24 (2), 118-131.

Curtis, H. (2015) Everyday Life \& the Unconscious Mind: An Introduction to Psychoanalytic Concepts. Chapter 2: “Trauma,” pp. 15-29. London: Karnac.

Danieli, Y., Brom, D., \& Sills, J. (2005) The Trauma of Terrorism: Sharing Knowledge and Shared Care, An International Handbook. Abingdon: Routledge.

Department of Education (2020) Expert panel to tackle educational underachievement. Belfast: Department of Education. Available at: https://www.education-ni.gov.uk/news/expert-panel-tackle-educationalunderachievement

Department of Health (2017) Statistics from the Northern Ireland substance misuse database 2016/17. Retrieved from:

https://www.health-ni.gov.uk/publications/statistics-northern-irelandsubstance-misuse-database-201617

Downes, C., Harrison, E., Curran, D. \& Kavanagh, M. (2012) The trauma still goes on...: The multigenerational legacy of Northern Ireland's conflict. Clinical Child Psychology and Psychiatry, 18(4), 583-603. DOI: 10.1177/1359104512462548

Fine Gael (2017) Statement by An Taoiseach, Leo Varadkar. $8^{\text {th }}$ December 2017. Available at: https://www.finegael.ie/statement-taoiseach-leo-varadkar-td/ 
Ganatra, S. (2018). Derry Girls: 'I'm not enjoying this bomb. I've an appointment at Tropicana at 12', The Irish Times, Wednesday 24th January 2018.

https://www.irishtimes.com/culture/tv-radio-web/derry-girls-i-m-not-

enjoying-this-bomb-i-ve-an-appointment-at-tropicana-at-12-1.3364502

Ganatra, S. (2019). Lisa McGee discusses the success of Derry Girls and femaleled comedies. Royal Television Society, March 2019. Retrieved from:

https://rts.org.uk/article/lisa-mcgee-discusses-success-derry-girls-and-female$\underline{\text { led-comedies }}$

Giffney, N. (2015) Sex as Evacuation. Studies in Gender and Sexuality. 16(2), 103109, DOI: $10.1080 / 15240657.2015 .1038156$

Giffney, N. (2021) The Culture-Breast: Cultural Experiences and the Psychoanalytic Clinic. London and New York: Routledge.

Hayward, K. \& McManus, C. (2019) Neither/Nor: The rejection of Unionist and Nationalist identities in post-Agreement Northern Ireland. Capital \& Class, 43 (1), 139-155.

Heaney, S. (1975) North. London: Faber.

Hinshelwood, R.D. (2008) 'Repression and splitting: Towards a method of conceptual comparison.' International Journal of Psychoanalysis, 89: 503-521.

Hinshelwood R.D. \& Fortuna, T. (2017) Melanie Klein: The Basics. London and New York: Routledge.

Howard, S. (2005) Psychodynamic Counselling in a Nutshell. London: Sage.

Joseph, B. (2005) 'The Paranoid-Schizoid Position' in S. Budd and R. Rusbridger (eds.), Introducing Psychoanalysis: Essential Themes and Topics. London and New York: Routledge. Chapter 2, 39-46. 
Kapur, R. (2001) Omagh: The beginning of the reparative impulse?

Psychoanalytic Psychotherapy, 15 (3), 265-278.

Kesey, K. (1962/1980) One flew over the cuckoo's nest. London: Pan Macmillan.

Klein, M. (1946) 'Notes on Some Schizoid Mechanisms' in M. Klein (1997; 1975), Envy and Gratitude and Other Works 1946-1963. London: Vintage. pp. 1-24.

Lemma, A. (2016) An Introduction to the Practice of Psychoanalytic Psychotherapy (2nd ed.). Chichester: Wiley Blackwell.

Mental Health Foundation (2016) Mental Health Foundation in Northern Ireland: Fundamental Facts 2016. London: Mental Health Foundation. Retrieved from: https://www.mentalhealth.org.uk > file > download

Mental Health Foundation (2018) WHILE YOUR BACK WAS TURNED: How mental health policymakers stopped paying attention to the specific needs of women and girls. London: Mental Health Foundation. Retrieved from: https://www.mentalhealth.org.uk/publications/mental-health-young-womenand-girls

Monaghan, R., \& McLaughlin, S. (2006). Informal Justice in the City. Space \& Polity, 10(2), 171-186. https://doi.org/10.1080/13562570600921667

Morrow, D. (2018) The lights are flashing red in Northern Ireland. The London School of Economics and Political Science, 12 $2^{\text {th }}$ October 2018.

https://blogs.lse.ac.uk/brexit/2018/10/12/the-lights-are-flashing-red-innorthern-ireland/

Muldoon, O.T. (2004) 'Children of the Troubles: The Impact of Political Violence in Northern Ireland', Journal of Social Issues. 60 (3): 453-468. 
Northern Ireland Statistics and Research Agency (2017) Suicide Statistics.

Retrieved from: https://www.nisra.gov.uk/publications/suicide-statistics O'Casey, S. (1924/1998) Juno and the Paycock. Sean O'Casey: Three Dublin Plays. London: Faber \& Faber.

O'Caollai, E. (2020) Explainer: Breaking the deadlock over an Irish Language Act. The Irish Times, Thursday 9th January 2020. Available at:

https://www.irishtimes.com/news/ireland/irish-news/explainer-breaking-the$\underline{\text { deadlock-over-an-irish-language-act-1.4135275 }}$

O’Neill, S. et al. (2015) Towards A Better Future: The Trans-generational Impact of the Troubles on Mental Health. Belfast: Commission for Victims and Survivors.

O’Neill, S. \& Hamber, B. (2018) Consultation Response “Addressing The Legacy Of Northern Ireland's Past". Retrieved from:

https://docs.wixstatic.com/ugd/198ed6_26add44b82674b4a8796d35f135f038 d.pdf

Quatman, T. (2015) Essential Psychodynamic Psychotherapy: An Acquired Art. London and New York: Routledge.

Sayers, J. (2004) Healing Aesthetics Kristeva through Stokes. Theory \& Psychology, 14 (6), 777-795.

Schubotz, D. \& O’Hara, M. (2011) 'A Shared Future? Exclusion, Stigmatization, and Mental Health of Same-Sex-Attracted Young People in Northern Ireland', Youth \& Society. 43 (2): 488-508.

Schrank, B. (1975) Dialectical configurations in Juno and the Paycock. Twentieth Century Literature, 21 (4), 438-456.

Seidler, V.J. (2013). Remembering 9/11. Terror Trauma and Social Theory. Basingstoke: Palgrave MacMillan. 
Tomlinson, M. (2012) 'War, peace and suicide: The case of Northern Ireland', International Sociology. 27 (4): 464-482.

Woodward, K. (2015) Psychosocial Studies: An Introduction. Chapter 8: "Trauma", pp. 113-123. London and New York: Routledge. 